\title{
Spectroradiometry vs. image analysis in colour measurement in juices from different orange and mandarin varieties
}

\section{Espectrorradiometría vs. digitalización y análisis de imágenes en la medida del color de zumos de diferentes variedades de naranja y mandarina}

\author{
Carla M. Stinco, Rocío Fernández-Vázquez, Francisco J. Heredia ${ }^{(\mathrm{S})}$, \\ Antonio J. Meléndez-Martínez, Isabel M. Vicario( ${ }^{*}{ }^{*}$ \\ Food Colour \& Quality Laboratory, Department Nutrition \& Food Science.Universidad de Sevilla 11 \\ Facultad de Farmacia, 41012 Sevilla, Spain. \\ (*) Email: vicario@us.es \\ S: miembro de SEDOPTICA / SEDOPTICA member \\ Received / Recibido: 26/02/2014. Revised / Revisado: 07/04/2014. Accepted / Aceptado: 29/04/2014. \\ DOI: http://dx.doi.org/10.7149/OPA.47.2.139
}

\begin{abstract}
:
In this work the colour of orange and mandarin juices from different varieties was evaluated by two instrumental methods: spectroradiometry and digital image analysis. The effect of the deepness and the background, and the validity of the colorimetric parameters obtained by both methodologies were explored to discriminate between groups. It was concluded that both methods allowed the discrimination between orange and mandarin juices, being spectroradiometry which provides the best classification.
\end{abstract}

Key words: Orange Juice, Mandarin Juice, Colour, Digital Image Analysis, Spectroradiometry.

\section{RESUMEN:}

En este trabajo se evalúa el color de zumos de naranja y mandarinas de distintas variedades medidos por dos métodos instrumentales: espectrorradiometría y digitalización y análisis de imagen. Se estudia el efecto del espesor y del fondo, y se explora la utilidad de los parámetros colorimétricos medidos por ambos métodos para diferenciar entre grupos. Se concluye que ambas técnicas permiten la discriminación entre zumos de naranja y mandarina siendo la espectrorradiometría la que proporciona la mejor clasificación.

Palabras clave: Zumo de Naranja, Zumo de Mandarina, Color, Digitalización y Análisis de Imagen, Espectrorradiometría.

\section{REFERENCES AND LINKS / REFERENCIAS Y ENLACES}

[1]. R. L. Huggart, P. J. Fellers, G. De Jager, J. Brady, "The influence of color on consumer preferences for Florida frozen concentrated grapefruit juices", Proc. Fla. State Hort Soc. 92, 148-151 (1979).

[2]. B. J. Tepper, "Effects of a slight color variation on consumer acceptance of orange juice", J. Sens. Stud. 8, 145-154 (1993). DOI

[3]. R. Fernández-Vázquez, L. Hewson, I. Fisk, D. Hernanz, F. J. Heredia, I. M. Vicario, J. Hort, "Colour influences sensory perception and liking of orange juice", Flavour 3, 1-8 (2014). DOI

[4]. C. Dhuique-Mayer, C. Caris-Veyrat, P. Ollitrault, F. Curk, M. J. Amiot, "Varietal and interspecific influence on micronutrient contents in Citrus from the Mediterranean area", J. Agric. Food Chem. 53, 2140-2145 (2005). DOI

[5]. C. Dhuique-Mayer, A. L. Fanciullino, C. Dubois, P. Ollitrault, "Effect of genotype and environment on citrus juice carotenoid content", J. Agric. Food Chem. 57, 9160-9168 52 (2009). DOI

[6]. CIE. CIE standard colorimetric observers. ISO/ CIE 10527: 1991 (E) (1991).

[7]. CIE. CIE standards colorimetric illuminants. ISO / CIE 10526: 1991 (E) (1991). 
[8]. CIE, Recommendations on Uniform Color Spaces, Color-Difference Equations, Psychometric Color Terms, CIE Publication No. 15 (E-1.3.1) (1971), Supplement 2, Bureau Central de la 57 CIE, Vienna (1978).

[9]. A. J. Meléndez-Martínez, I. M Vicario, F. J. Heredia, "Influence of white reference measurement and background on the color specification of orange juices by means of diffuse reflectance spectrophotometry", J. AOAC Int. 89, 452-457 (2006).

[10]. C. Stinco, R. Fernández-Vázquez, M. L. Escudero-Gilete, F. J. Heredia, A. J. Melendez-Martinez, I. M. Vicario, "Effect of orange juice's processing on the color, particle size, and bioaccessibility of carotenoids", J. Agric. Food Chem. 60, 1447-1455 (2012). DOI

[11]. C. Stinco, R. Fernández-Vázquez, A. J. Meléndez-Martínez, F. J. Heredia, E. Bejines-Mejías, I. M. Vicario, "Influence of different backgrounds on the instrumental color specification of orange juices", pp. 143150 in Color in Food. Technologigal and Psychophysical Aspects, J. Caivano, M. Buera Etds., CRC Press. Taylor \& Francis Group, New York (2012).

[12]. R. Fernández-Vázquez, C. M. Stinco, D. Hernanz, F. J. Heredia, I. M. Vicario, “Colour training and colour differences thresholds in orange juice", Food Qual. Prefer. 30, 320-327 (2013). DOI

[13]. M. R. Luo, G. Cui, B. Rigg, "The development of the CIE 2000 colour-difference formula: CIEDE2000", Color Res. Appl. 26, 340-350 (2001). DOI

[14]. F. J. Heredia, M. L. González-Miret, C. Álvarez, A. Ramírez, DigiFood® (Análisis de imagen). [No. SE01298.] (2006).

[15]. K. León, D. Mery, F. Pedreschi, J. León, “Color measurement in L*a*b* units from RGB digital images”, Food Res. Int. 39, 1084-1091 (2006). DOI

[16]. R. Rocha Latado, P. Christovam Tognato, M. E. Silva-Stenico, L. Magali do Nascimento, P. César dos Santos, "Accumulation of anthocyanins and characteristics of fruits of blood oranges during cold storage", Rev. Bras. Frut. 30, 604-610 (2008).

[17]. R. Fernández-Vázquez, C. Stinco, A. J. Melendez-Martinez, F. J. Heredia, I. M. Vicario, "Visual and instrumental evaluation of orange juice color: a consumers' preference study", J. Sens. Stud. 26, 436444 (2011). DOI

[18]. H. S. Lee, "Characterization of carotenoids in juice of red navel irange (Cara Cara)", J. Agr. Food Chem., 49, 2563-2568 (2001). DOI

\section{Introduction}

Colour is one of the most important sensory attributes, which have direct influence in acceptance and perception of the quality by consumers [1-3]. Orange and mandarin juice colour ranges from pale yellow at the beginning of the harvest to red-orange at the end. Each variety has a characteristic colour, although this can vary depending on agronomic and climatic factors $[4,5]$.

Instrumental colour measurements are simple, accurate and versatile, and moreover they eliminate the subjectivity associated with visual measurements. There are different instruments for evaluating juice colour, such as colorimeters, spectrophotometers and spectroradiometers, but, independently of the instrument used, it is very important to define measurements conditions correctly. CIE (International
Commission on Illumination) recommends observers [6], illuminants [7], and colour spaces [8] in order to normalize objective colour measurement. It must be also taken into account sample position, system geometry, light source intensity, sample deepness, blank measurement, background and surrounding $[9,10]$.

Digital image analysis (DIA) is being used increasingly for instrumental food colour specification. This methodology is based on the acquisition of an image and its post analysis, through which it can be obtained not only the colour but also the appearance of the sample, giving much more detailed information, as the colour distribution in the sample.

The objectives of this study were to check, the differences between spectroradiometry (SP) and digital image analysis (DIA) to characterize juice colour from different orange and mandarin 
TABLE I

Orange and mandarin varieties analyzed.

\begin{tabular}{|c|c|c|c|c|c|}
\hline \multicolumn{2}{|r|}{ Mandarins } & \multicolumn{4}{|c|}{ Oranges } \\
\hline M1 & Orogranue & V1 & Navelina & V12 & Navel Barnfield \\
\hline M2 & Beatriz & V2 & Fukumoto & V13 & Rhode Summer \\
\hline M3 & Prenules & V3 & Fisher & V14 & Nave late \\
\hline M4 & Loretina & V4 & Navel Foyos & V15 & Navel Lane Late \\
\hline M5 & Clemen Rubí & V5 & Cadenera & V16 & Navel Chislett \\
\hline M6 & Mioro Coppola & V6 & Salustiana & V17 & Sanguinelli \\
\hline \multirow[t]{5}{*}{ M7 } & Arrufatina & V7 & Ambersweet & V18 & Valencia Midknight \\
\hline & & V8 & Navel Cara Cara & V19 & Rhode Late \\
\hline & & V9 & Pera & V20 & Valencia Delta \\
\hline & & V10 & Navel Powell & V21 & Barberina \\
\hline & & V11 & Shamoutti & V22 & Hamlin \\
\hline
\end{tabular}

varieties and to determine which methodology offers a better discrimination among samples.

\section{Material and methods}

\subsection{Samples}

22 orange and 7 mandarin varieties cultivated in Spain in 2010-2011 were analysed (Table I). Juices were obtained using a domestic squeezer.

\subsection{Colour measurement: Spectroradiometry (SP)}

Juice colour was measured in a CAS 140 B spectroradiometer (Instrument Systems,Munich, Germany) with an external incandescent lamp, equipped with a Top telescope optical probe (Instrument Systems, Munich, Germany) [11] and a Tamron zoom mod. SP 23A (Tamron USA, Inc., Commack, NY, USA) using a grey surrounding $\left(L^{*}=50\right)$ and white and black backgrounds in two different containers: $10 \mathrm{~mm}$ pathlength (deepness) plastic cuvettes and 29 mm deepness bottles (Fig. 1) [12].

\subsection{Colour measurement: Digital image analysis (DIA)}

The DigiEye ${ }^{\circledR}$ imaging system including a calibrated digital camera Nikon D80 (Nikon Corporation, Tokyo, Japan) connected to an illumination box designed by VeriVide Ltd. (Leicester, UK) was used to capture the digital images [13].

Samples placed in transparent plastic bottles of $29 \mathrm{~mm}$ deepness (Fig. 1) [12] and illuminated by a diffuse D65 simulator were measured against a

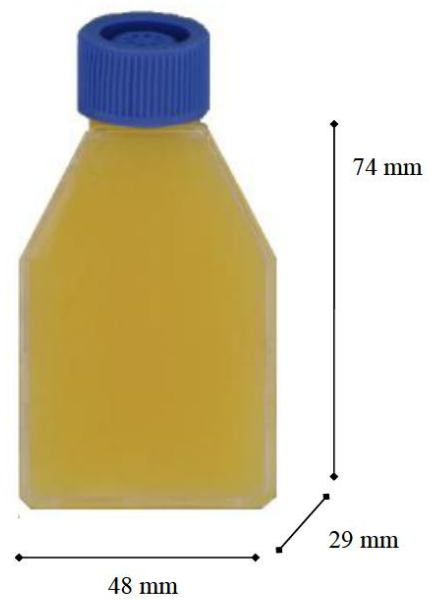

Fig. 1. Characteristics of the bottles used for containing the samples in colour measurements.

grey surrounding $\left(L^{*}=50\right)$ and white and black background. From each image, CIELAB parameters were obtained using DigiFood $\AA$ software [14] which allows the transformation of RGB values into the CIELAB colour parameters [15].

\section{Results and discussion}

\subsection{Instrumental colour measurement}

Figures 2 and 3 show the distribution in the $a^{*} b^{*}$ colour diagram of the orange and mandarin juices analyzed by SP (Fig. 2) and DIA (Fig. 3)

under the usual conditions (grey surrounding, $L^{*}=50$, and white background, and cuvette of 1 
$\mathrm{mm}$ in SP and bottles of $29 \mathrm{~mm}$ deepness in DIA). Lightness is also shown.

It can be observed that all the juices were located in the first quadrant, in the yellowish and orangish zone. While in SP measurements (Fig. 2(a)) both groups of juices appeared well differentiated (excepting some orange varieties), in DIA the separation was not so clear (Fig. 3(a)). When measured by SP (Fig. 2(b)) Sanguinelli variety was the darkest $\left(L^{*}=33.33\right)$ followed by all mandarin varieties $\left(L^{*}=63.49-66.54\right)$. This method allowed a defined separation between orange and mandarin juices except Sanguinelli variety. When colour samples were determined by DIA, separation according to lightness was not so evident (Fig. 3(b)).

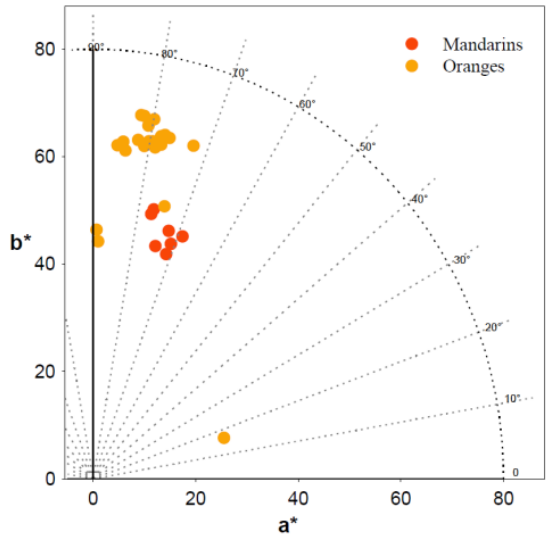

(a)

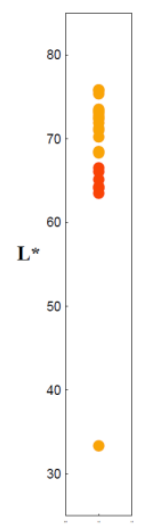

(b)
Fig. 2. (a) $a^{*} b^{*}$ colour diagram and (b) $L^{*}$ for SP measurements.

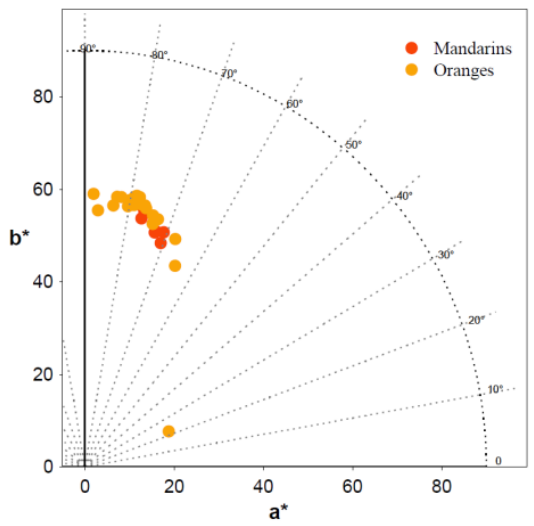

(a)

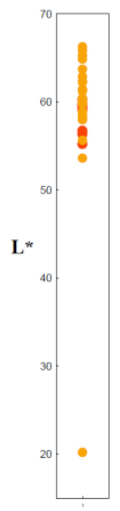

(b)
Fig. 3. (a) $a^{*} b^{*}$ colour diagram and (b) $L^{*}$ for DIA measurements.
In both methodologies, Sanguinelli variety was the juice with less chroma, followed by mandarin juices and some orange varieties. In respect to hue, measured by $\mathrm{SP}$, both types of samples were separated with the exception again of Sanguinelli which showed a hue of $17^{\circ}$, an atypical colouring due to its high content of anthocyans (pigments responsible of the red colour) [16]. This separation in hue was not appreciated when samples were measured by DIA.

In general, mandarin juices were darker, less vivid and more orangish, and among the orange juices, Fukumoto and Navelate varieties showed the highest values for hue, which means they were the most yellowish by both methods.

\subsection{Relationship between DIA and SP measurements}

In order to evaluate the effect of the methodology (DIA or SP) and the different deepness used (10 and $29 \mathrm{~mm})$, simple correlations between $L^{*}, a^{*}, b^{*}, C^{*}{ }_{a b}$ and $h_{a b}$ were determined.

In all the cases studied, correlations were significant (Table II). Independently of the background used, it was observed that the best correlations were obtained comparing values from both deepness with SP. When comparing the two methods SP and DIA, with the same deepness, the best correlation was obtained for hue $\left(r^{*}>0.97\right)$, and the lowest correlation was obtained for chroma $\left(r^{*}>0.75\right)$. Finally, comparing different methods and deepness, the lowest correlation was also found for chroma $\left(r^{*}>0.61\right)$, while the highest was for hue $\left(r^{*}>0.97\right)$. Regarding the backgrounds, in general, better correlations were obtained in white background.

Obviously, differences between methods must be due mainly to the way the colorimetric coordinates are calculated, since the samples suffer scarce handling. DIA implies the transformation of the image into RGB coordinates and then, into CIELAB coordinates using mathematical models. On the other hand, SP uses the spectral distribution of radiant energy and, from it, CIELAB coordinates are obtained mathematically, according to CIE 
TABLE II

Simple correlation coefficients.

\begin{tabular}{|c|c|c|c|}
\hline \multicolumn{4}{|c|}{ White background } \\
\hline $\begin{array}{c}\text { Method } \\
\text { Deepness }\end{array}$ & $\begin{array}{c}\text { SP } \\
10 / 29 \mathrm{~mm}\end{array}$ & $\begin{array}{c}\text { SP/DIA } \\
29 / 29 \mathrm{~mm}\end{array}$ & $\begin{array}{c}\text { SP/DIA } \\
10 / 29 \mathrm{~mm}\end{array}$ \\
\hline$L^{*}$ & 0.97 & 0.94 & 0.90 \\
\hline$a^{*}$ & 0.90 & 0.93 & 0.91 \\
\hline$b^{*}$ & 0.99 & 0.85 & 0.80 \\
\hline$C^{*}{ }_{a b}$ & 0.98 & 0.79 & 0.69 \\
\hline$h_{a b}$ & 0.99 & 0.98 & 0.98 \\
\hline
\end{tabular}

\section{Black background}

\begin{tabular}{|c|c|c|c|}
\hline \multicolumn{4}{|c|}{ Black background } \\
\hline $\begin{array}{c}\text { Method } \\
\text { Deepness }\end{array}$ & $\begin{array}{c}\text { SP } \\
10 / 29 \mathrm{~mm}\end{array}$ & $\begin{array}{c}\text { SP/DIA } \\
29 / 29 \mathrm{~mm}\end{array}$ & $\begin{array}{c}\text { SP/DIA } \\
10 / 29 \mathrm{~mm}\end{array}$ \\
\hline$L^{*}$ & 0.93 & 0.92 & 0.80 \\
\hline$a^{*}$ & 0.93 & 0.97 & 0.93 \\
\hline$b^{*}$ & 0.95 & 0.83 & 0.72 \\
\hline$C^{*}{ }_{a b}$ & 0.94 & 0.75 & 0.61 \\
\hline$h_{a b}$ & 0.98 & 0.99 & 0.97 \\
\hline
\end{tabular}

recommendation [8]. Anyway, it is important to highlight DIA and SP correlate better when the same deepness is used. Previous studies concluded that the slight variations observed in the colour coordinates values measured by both techniques could be also due to differences in the deepness of the sample, and to other secondary factors such as illumination conditions, or the effect of the surface of the container [17].

\subsection{Linear discriminant analysis (LDA)}

To check if it is possible to discriminate mandarin and orange juices attending to colour, multivariate analyses (LDA) were done with colorimetric parameters obtained by DIA and SP (Fig. 4). The aim was to determine which of the measurements lead to the best discrimination between both types of samples studied.

LDA done with values obtained by SP in cuvette of $10 \mathrm{~mm}$ deepness in both backgrounds resulted in a mathematical model which included five variables $\left(L^{*}, a^{*}, b^{*}, C^{*}{ }_{a b}\right.$ and $\left.h_{a b}\right)$ and a $100 \%$ correct classification $(p<0.001)$. When the analyses considered $29 \mathrm{~mm}$ deepness, the model selected also the same five variables but only $a^{*}, b^{*}$ and $C^{*}{ }_{a b}$ for white background and $L^{*}, a^{*}, b^{*}$ and $C^{*}{ }_{a b}$ for black background were significant. In both analyses the model allowed a $97 \%$ correct classification $(p<0.001)$ being the Cara Cara variety the one which was wrongly classified. This variety is characterised by its more reddish colour, because it contains lycopene [18].

For measurements done by DIA in $29 \mathrm{~mm}$ deepness, the model included the five variables $\left(L^{*}, a^{*}, b^{*}, C^{*}{ }_{a b}\right.$ and $\left.h_{a b}\right)$ being $a^{*}, b^{*}$ and $C^{*}{ }_{a b}$ significant for white background and only $a^{*}$ for the black one, with percentages of $83 \%$ and $90 \%$
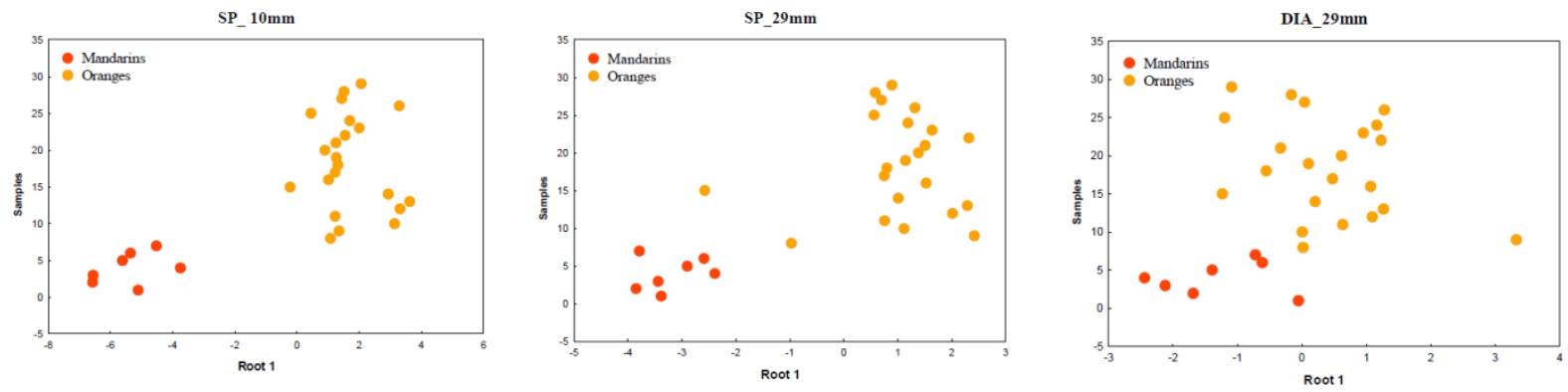

SP $10 \mathrm{~mm}$
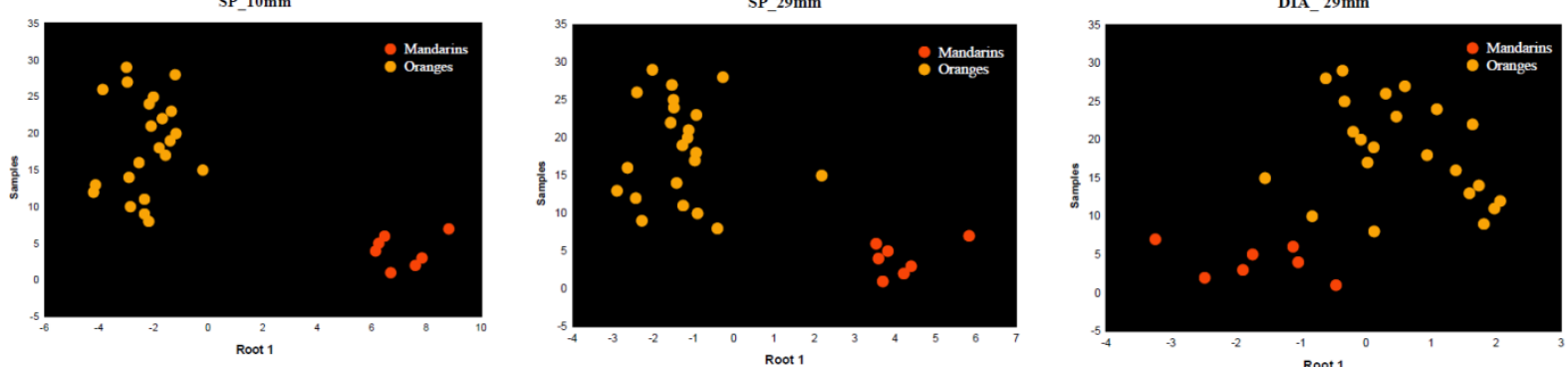

Fig. 4. Scatterplot of the samples in planes defined by the canonical function when type of citric is considered for discrimination. 
of correct classifications respectively. In this case, the samples wrongly classified did not show any highlighted characteristics.

\section{Conclusions}

In conclusion, although DIA and SP have a good correlation, according to the results obtained, SP in cuvette $(10 \mathrm{~mm}$ deepness $)$ provides the best discrimination between orange and mandarin juices. These results confirm the utility of this technique for colour measurements in homogeneous colour samples.

\section{Acknowledgments}

This work was supported by funding from the Consejería de Innovación Ciencia y Empresa, Junta de Andalucía by the project P11-AGR7783. The authors are members of the IBERCAROT network, funded by CYTED (ref. 112RT0445). The authors acknowledge the collaboration of Augusto Carmona García-Olalla for providing samples of oranges and mandarins. 